\title{
Productivity Prediction Model of Vertical Artificial Fracture Well and Analysis of Influence Factor in Low Permeability Reservoir
}

\author{
Chengli Zhang ${ }^{*}$, Dezhi Liang $^{1}$, Daiyin Yin $^{1}$ and Guoliang Song ${ }^{2}$ \\ ${ }^{I}$ Key Laboratory of Enhanced Oil and Gas Recovery of Ministry of Education, Northeast Petroleum University ${ }^{\text {, }}$ \\ Daqing, 163318, China \\ ${ }^{2}$ College of Mathematics and Statistics, Northeast Petroleum University, Daqing, 163318, China
}

\begin{abstract}
Based on the analysis of seepage mechanism of fracturing wells in low permeability reservoir, this paper establishes the capacity model of the vertical fractured well production under the factors of Start-up pressure gradient, pressure sensitive effect and the artificial fracture length. The numerical simulation is compiled and software calculates the capacity model by using numerical simulation. This simulation technique verifies the validity of the model and numerical method. On this basis, we study the influence of the included angle of artificial fracture and well array direction, artificial fracture length, start-up pressure gradient and production pressure difference to the capacity of the oil well.
\end{abstract}

Keywords: low permeability reservoirs; the capacity equation of the vertical fractured well; fracture length; start-up pressure gradient; well array direction.

\section{INTRODUCTION}

Low permeable oil fields have a poor reservoir property, heterogeneity is strong, development is difficult and economic benefit is poor. So strengthening the research of the percolation mechanism of low permeability reservoir and the development with the new exploitation technology, constant improvements to the level of low permeability oil and gas field development are achieved. The best economic benefits is the top priority of the development of the oil industry today [1-5]. In the light of the characteristics of low permeable oil fields, we must establish unique development mode of low permeable oil fields. Infilled pattern, integral fracturing and strengthening water injection are recognized mining method and their purpose is to encrypt well pattern at home and abroad. Vertical fracture wells are widespread in the low permeability reservoir, this is because most of the production wells in low permeability reservoir would have production capacity only after fracturing and reconstruction is carried out, that is fracturing is the main mining methods for improving the productivity of oil well. So, the production capacity of vertically fractured well has a great influence to low permeability oil field exploitation. In recent years, there are many studies which have investigated the vertically fractured wells [6-8]. But these studies failed to fully consider the length and direction of fractures. To overcome this, this article will build the vertically fractured wells capacity model in low permeability reservoir considering start-up pressure gradient [9-12], pressure sensitive effect $[12-15]$ and length $[16,17]$ and direction $[18,19]$ of fractures. It will also analyze the influencing factors to capacity.

\section{ESTABLISHMENT OF THE MATHEMATICAL MODEL}

A large number of studies have shown that when the vertical fractured well is in production state, it induces twodimensional elliptic seepage in the stratum and will form the conjugate isobaric elliptical equipotential line and hyperbola streamline group which uses the fractures endpoint as the main focus [20]. So it is more close to reality to use the elliptic coordinates to describe the vertical fractured well seepage physical process.

Assumptions for hypothesis model of vertical fracture wells are summarised as follows:

(1) Reservoir is isochoric, isotropic, homogeneous and horizontal.

(2) The artificial fracture is symmetrical about wellbore, wings vertical fractures and causes no pressure drop within the fracture.

(3) Regardless of the failure of fractures with the extension of time.

(4) Considering the start-up pressure of gradient nondarcy seepage.

(5) Considering the effect of pressure sensitive effect. Ignore the capillary force and gravity.

The relation between rectangular coordinate and elliptic coordinates is 


$$
\begin{aligned}
& \left\{\begin{array}{l}
a=x_{f} \cosh \xi \\
b=x_{f} \sinh \xi
\end{array}\right. \\
& \left\{\begin{array}{l}
x=a \cos \eta \\
y=b \sin \eta
\end{array}\right.
\end{aligned}
$$

where $\eta 、 \xi$ is elliptic coordinates; $x_{f}$ is half length of fracture; $a$ is the elliptical semi-major axis; $b$ is the elliptical short half shaft.

From this relationship, we get the isobaric ellipse and hyperbolic group.

$\frac{x^{2}}{a^{2}}+\frac{y^{2}}{b^{2}}=1$

$\frac{x^{2}}{x_{f}^{2} \cos ^{2} \eta}+\frac{y^{2}}{x_{f}^{2} \sin ^{2} \eta}=1$

Based on the concept of disturbed ellipse, using the developmental rectangle group

$$
\left\{\begin{array}{l}
\bar{x}=x_{f} \cosh \xi \\
\bar{y}=\frac{2}{\pi} \int_{0}^{\frac{\pi}{2}} y d y=\frac{2 x_{f}}{\pi} \sinh \xi
\end{array}\right.
$$

to describe the isobaric elliptic group.

Assuming that the production is $Q$, so the seepage velocity through any seepage section can be expressed as:

$v(\xi)=\frac{Q}{4 h x_{f} \cosh \xi}$

Considering start-up pressure gradient.

$v=\frac{Q}{4 h x_{f} \cosh \xi}=\frac{k}{\mu}\left(\frac{d p}{d y}-\lambda\right)$

And because there are pressure-sensitive effect [21], and the change of permeability with pressure meet $k=k_{0} \exp \left[-\alpha\left(P_{e}-P\right)\right]$. Plug in the above type.

$\frac{Q}{4 h x_{f} \cosh \xi}=\frac{k}{\mu} e^{\alpha\left(P-P_{0}\right)}\left(\frac{d p}{d y}-\lambda\right)$

where $\frac{d P}{d \bar{y}}=\frac{d P}{d \xi} \cdot \frac{d \xi}{d \bar{y}}, \alpha$ is media deformation coefficient; $k_{0}$ is the original reservoir permeability.

Because in rectangular group

$\bar{y}=\frac{2}{\pi} \int_{0}^{\frac{\pi}{2}} y d y=\frac{2 x_{f}}{\pi} \sinh \xi$

So

$\frac{d \bar{y}}{d \xi}=\frac{2 x_{f} \cosh \xi}{\pi}$ $\frac{d P}{d \bar{y}}=\frac{d P}{d \xi} \cdot \frac{\pi}{2 x_{f} \cosh \xi}$

Plug in the type (8):

$\frac{Q}{4 h x_{f} \cosh \xi}=\frac{k_{0}}{\mu} e^{\alpha\left(P-P_{0}\right)}\left(\frac{d P}{d \xi} \cdot \frac{\pi}{2 x_{f} \cosh \xi}-\lambda\right)$

Simplify, getting

$\frac{d P}{d \xi}-\frac{Q \mu}{2 \pi k_{0} h} e^{\alpha\left(P-P_{0}\right)}=\frac{2 \lambda x_{f}}{\pi} \cosh \xi$

Taking $E(P)=e^{\alpha P}$, so $E_{0}=e^{\alpha P_{0}}$.

and

$\frac{d E}{d P}=\alpha e^{\alpha P}, \frac{d E}{d \xi}=\frac{d E}{d P} \cdot \frac{d P}{d \xi}=\alpha e^{\alpha P} \frac{d P}{d \xi}$

So

$\frac{d P}{d \xi}=\frac{d P}{d E} \cdot \frac{d E}{d \xi}=\frac{1}{\alpha e^{\alpha P}} \cdot \frac{d E}{d \xi}$

Plug in the type (13):

$\frac{d E}{d \xi}-\frac{2 \alpha \lambda x_{f} \cosh \xi}{\pi} \cdot E=\frac{Q \mu \alpha E_{0}}{2 \pi k_{0} h}$

The above type is the first-order linear equation such as $\frac{d p}{d x}+p(x) y=q(x)$, and it's general solution is:

$y=e^{-\int_{x 0}^{x} p(t) d t}\left(c+\int_{x_{0}}^{x} q(t) e^{\int_{x 0}^{x} p(s) d s} d t\right)$

Make $A=\frac{2 \alpha \lambda x_{f}}{\pi}, B=\frac{Q \mu \alpha}{2 \pi k_{0} h}$.

Aiming at the problem of this article, $p(x)=-A \cosh \xi$, $q(x)=B E_{0}$, and it's general solution is:

$E(\xi)=e^{\int_{\xi e}^{\xi} A \cosh \xi}\left(c+\int_{\xi e}^{\xi} B E_{0} e^{\iint_{\xi \varepsilon}^{\xi}-A d t} d t\right)$

Plug in the outer boundary conditions $E(\xi)=E_{0}=e^{\alpha P}$ :

$c=e^{\alpha P}$

So

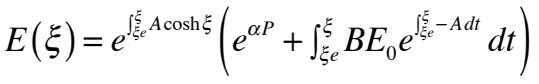

where

$e^{\int_{\xi_{e}}^{\xi} A \cosh \xi}=e^{\frac{2 \alpha \lambda x_{f}}{\pi}\left(\sinh \xi-\sinh \xi_{e}\right)}$

$\int_{\xi_{e}}^{\xi} B E_{0} e^{\int_{\xi_{e}}^{\xi}-A d t} d t=\frac{Q \mu \alpha}{2 \pi k_{0} h} \cdot e^{\alpha P_{0}} \int_{\xi_{e}}^{\xi} e^{\frac{2 \alpha \lambda x_{f}}{\pi}\left(\sin \xi_{e}-\sinh t\right)} d t$

Plug in the above type: 
$E(\xi)=e^{\frac{2 \alpha \lambda x_{f}}{\pi}\left(\sinh \xi-\sinh \xi_{e}\right)}\left(e^{\alpha P_{0}}+\frac{Q \mu \alpha}{2 \pi k_{0} h} \cdot \int_{\xi_{e}}^{\xi} e^{\frac{2 \alpha \lambda x_{f}}{\pi}\left(\sin \xi_{e}-\sinh t\right)} d t\right)$

Take a logarithmic type on both sides:

$P(\xi)=\frac{2 \lambda x_{f}}{\pi}\left(\sinh \xi-\sinh \xi_{e}\right)+P_{0}+L(\xi)$

where $L(\xi)=\frac{1}{\alpha} \ln \left[1+\frac{Q \mu \alpha}{2 \pi k_{0} h} \int_{\xi_{e}}^{\xi} e^{\frac{2 \alpha \lambda x_{f}}{\pi}\left(\sin \xi_{e}-\sinh t\right)} d t\right]$

Due to the boundary conditions (when $\xi=0, P(0)=P_{w}$ ):

$P_{w}=P(0)=\frac{2 \lambda x_{f}}{\pi}\left(\sinh 0-\sinh \xi_{e}\right)+P_{0}+L(0)$

where $L(0)=\frac{1}{\alpha} \ln \left[1+\frac{Q \mu \alpha}{2 \pi k_{0} h} \int_{\xi_{e}}^{0} e^{\frac{2 \alpha \lambda x_{f}}{\pi}\left(\sin \xi_{e}-\sinh t\right)} d t\right]$

So

$Q=\frac{2 \pi k_{0} h}{\mu \alpha} \cdot \frac{e^{\alpha\left[P_{w}-P_{0}-\frac{2 \lambda x_{f}}{\pi}\left(\sinh 0-\sinh \xi_{e}\right)\right]}}{\int_{\xi_{e}}^{0} e^{\frac{2 \alpha \lambda x_{f}}{\pi}\left(\sinh \xi_{e}-\sinh t\right)} d t}$

\section{PRODUCTIVITY PREDICTION MODEL VALIDATION}

Because the integrand of the type is non-integrable, we have adopted Simpleson integral method for solving after the construction of the mathematical model and this is calculate by using computer programming. First of all, we have a actual verification in artificial vertical fractured well of a field. To compare the forecast curve and the actual curve in Fig. (1) we can see the coincidence degree of two curves is good and relative error of production is smaller. In the process of the model application to calculate, because we fit some important parameters with the measured data, the calculated result is in accordance with the actual production and can meet the requirements of engineering calculation.

\section{ANALYSIS OF PRODUCTIVITY INFLUENCE FACTOR IN VERTICAL FRACTURE WELL}

Through the instance, we analyzed the influence of the included angle of artificial fracture and well array direction, artificial fracture length, start-up pressure gradient and production pressure difference to the capacity of the oil well separately. Parameter values calculated are: $x_{f}=45 \mathrm{~m}$, $\Delta P=16.67 \mathrm{MPa}, k_{0}=5 \times 10^{-3} \mu \mathrm{m}^{2}, \mu=36.07 \mathrm{mPa} \cdot \mathrm{s}$, $h=8.5 \mathrm{~m}, a=200 \mathrm{~m}, r_{w}=0.2 \mathrm{~m}, \alpha=0.02 \mathrm{MPa}^{-1}$, $(K b)_{f}=25 \mathrm{D} \cdot \mathrm{cm}, \alpha=0.02 \mathrm{MPa}^{-1}, \lambda=0.02 \mathrm{MPa} / \mathrm{m}$.

\subsection{Angle of Artificial Fracture and Well Array Direction}

Design angles of artificial fracture and well array direction are $0^{\circ}, 12.5^{\circ}, 22.5^{\circ}$ and $45^{\circ}$ separately. The production and recovery factor under the different angles is achieved by numerical calculation as shown in Figs. $(\mathbf{2}, \mathbf{3})$.

From the chart above we can conclude that as the angle of artificial fracture and well array direction increases, the tired production reduces gradually. When the angle is $0^{\circ}$, the tired oil production is highest, and recovery rate reaches $23.56 \%$. This is because the injected water formed the propulsion from injection well array to production well array along the fractures when it Jumped into the injection well array. Sweep efficiency was improved and water breakthrough time of production well array is delayed at the same time. When the angle of artificial fracture and well array direction is $12.5^{\circ}$ and $22.5^{\circ}$, well spacing along the direction of fracture is so long that can ease the contradiction on the early water breakthrough and violently water of the oil well along the direction of fracture. It also delayed the

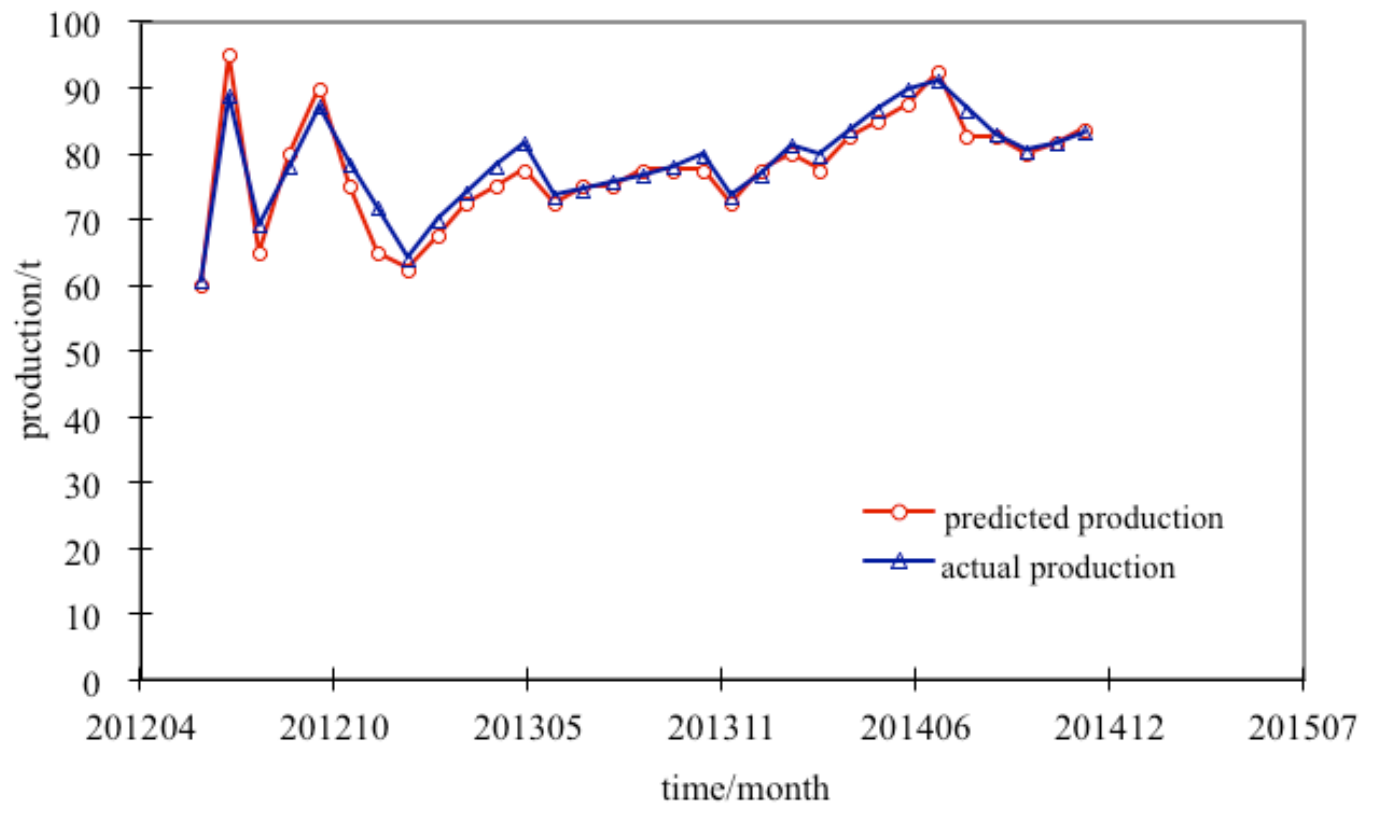

Fig. (1). Production prediction results. 


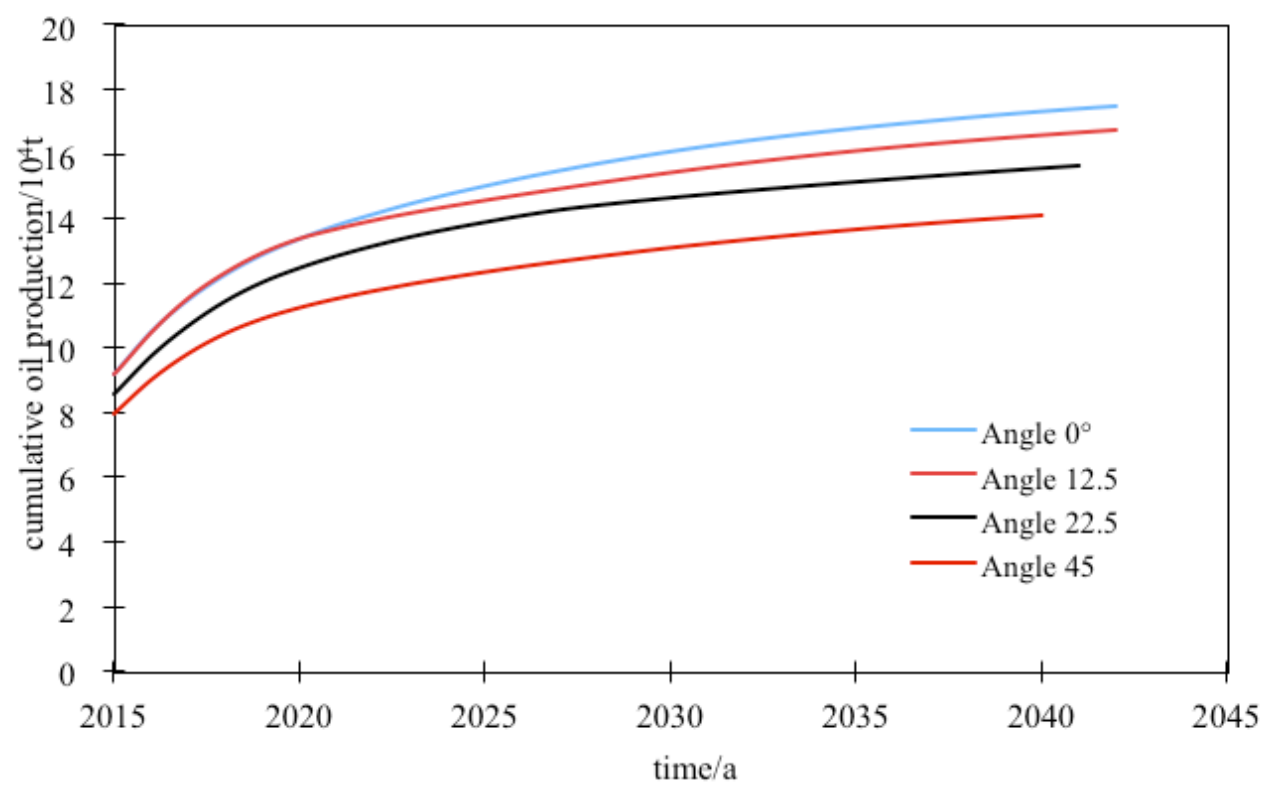

Fig. (2). Cumulative oil production under different angle of artificial fracture and well array direction.

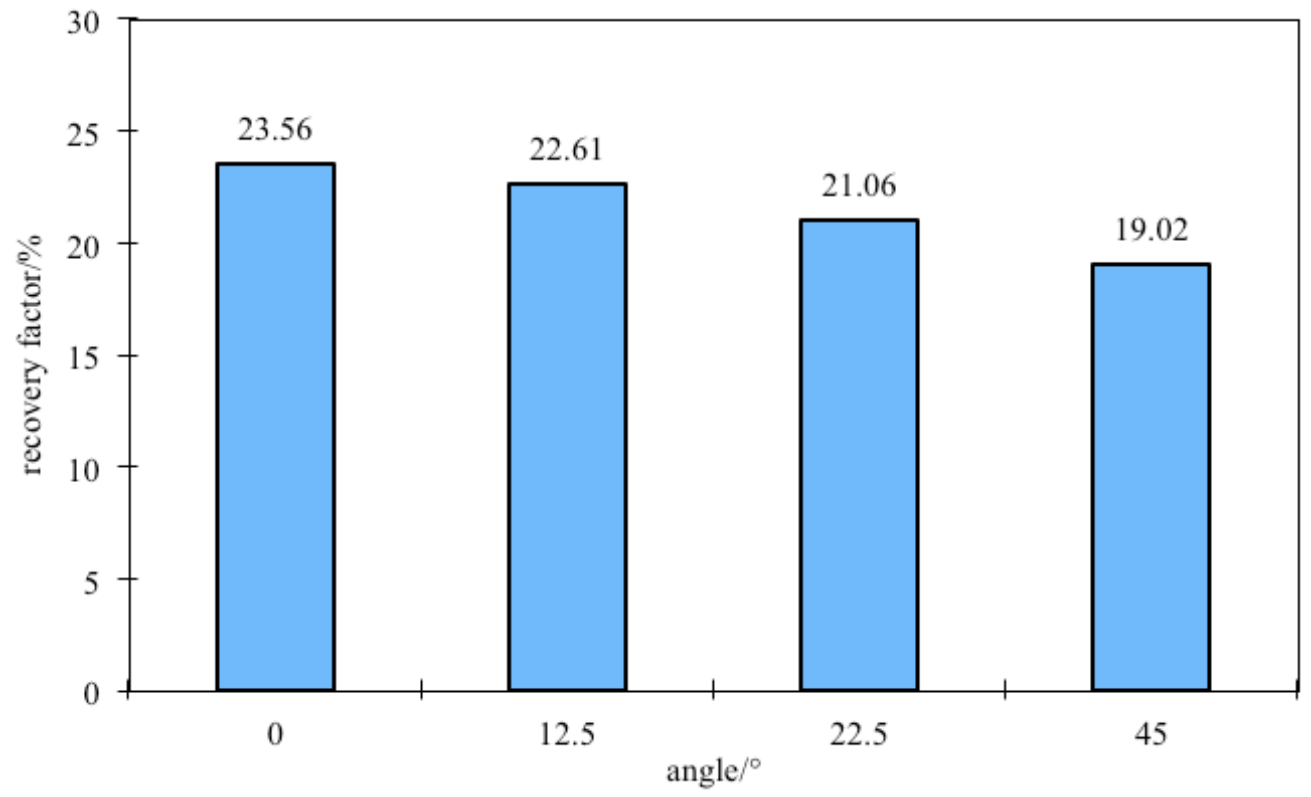

Fig. (3). Recovery factor under different angle of artificial fracture and well array direction.

water breakthrough time of injection production wells on both sides. But at some time, the water from injection well would run through along the direction of fracture and form a new line with the production well two wells apart. So every production well will form a line with water injection well. The moisture content will rise rapidly and it is difficult to be adjusted. When the angle of artificial fracture and well array direction is $45^{\circ}$, the moisture content is high, and recovery efficiency is low. Mainly because the fracture direction pointing in the direction of injection wells leads to part of the wells water flooded too early. At the same time the reducing swept area leads to low recovery efficiency. So when the angle of artificial fracture and well array direction is $0^{\circ}$, the development effect is the best.

\subsection{Artificial Fracture Length}

The different artificial fracture lengths are designed as $30 \mathrm{~m}, 35 \mathrm{~m}, 40 \mathrm{~m}, 45 \mathrm{~m}, 50 \mathrm{~m}, 55 \mathrm{~m}$ and $60 \mathrm{~m}$ separately and the production under the different artificial fracture length is achieved as shown in Fig. (4).

From the curve above it can be inferred that with the increase of oil well fracture length, the connectivity of oil and water wells and the formation is getting better and daily oil well is getting higher. But when the artificial fracture length is more than $40 \mathrm{~m}$, the increased size of the daily oil production became smaller. This is due to the filtrational resistance in the artificial fracture. If the fracture in the seepage resistance is longer from the fracture flow to the 


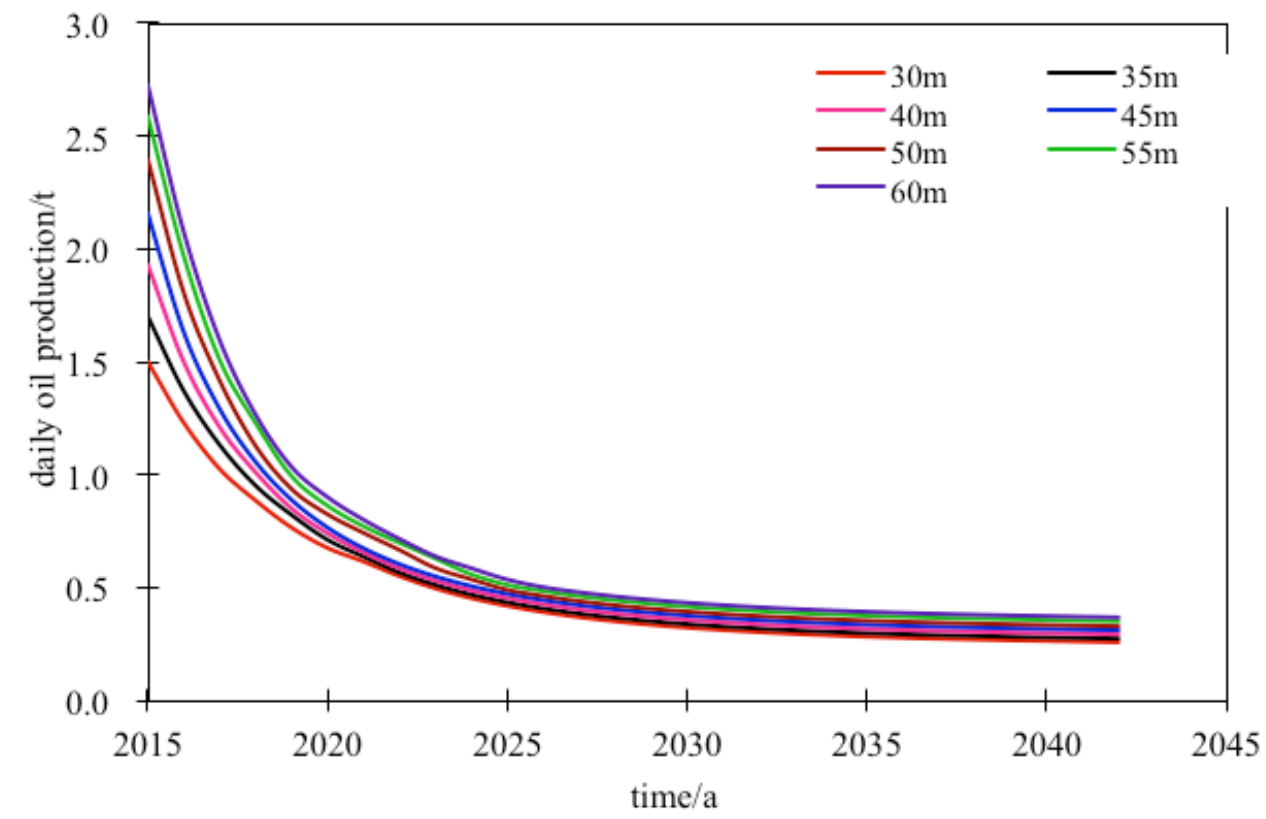

Fig. (4). Daily oil production under the different artificial fracture length in oil well.

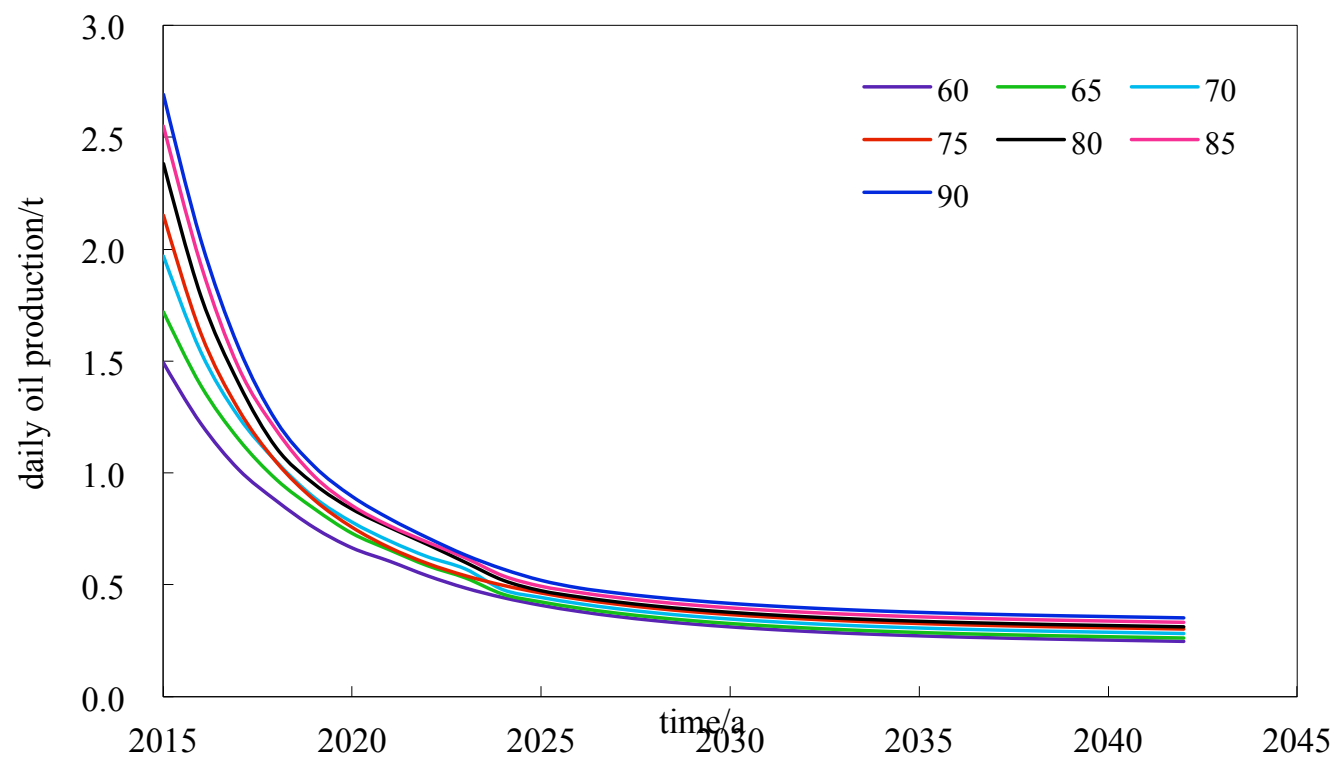

Fig. (5). Daily oil production under the different artificial fracture length in water well.

bottom, the impact on the capacity will also be getting stronger. With the increase of production time, daily oil production curve in water well under the different artificial fracture length gets closer. At this time, increase in the fracture length has no effect to improve the single oil well produced, so the best oil well fracture length is $40-50 \mathrm{~m}$.

By using the same technique, we can draw daily oil production curve in water well under the different artificial fracture length as shown in Fig. (5). From the curve above it can be seen that with the increase of well fracture length, the connectivity of oil and water wells and the formation is getting better and daily oil well is getting higher. But when the artificial fracture length is more than $70 \mathrm{~m}$, the increase size of the daily oil production became smaller. This is because there is filtrational resistance in the artificial fracture. The longer the fracture is, the seepage resistance from the fracture flow to the bottom will be higher and the impact on the capacity is also getting stronger. With the increase of production time, daily oil production curves in water well under the different artificial fracture length gets closer. At this time, increase in the fracture length has no effect to improve the single oil well produced, so the best oil well fracture length is $70-80 \mathrm{~m}$.

\subsection{Start-Up Pressure Gradient}

Design the different start-up pressure gradients as $0.005 \mathrm{MPa} / \mathrm{m} 、 0.01 \mathrm{MPa} / \mathrm{m} 、 0.015 \mathrm{MPa} / \mathrm{m} 、 0.02 \mathrm{MPa} / \mathrm{m}$ 、 


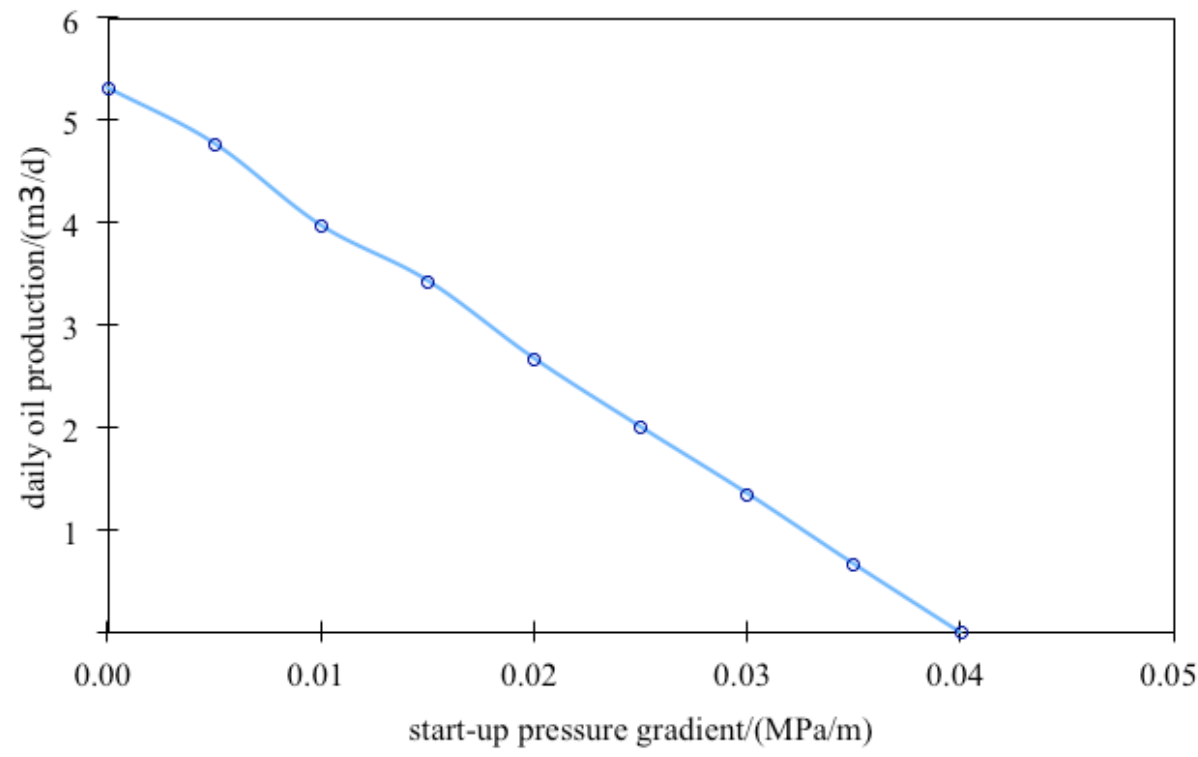

Fig. (6). Relationship curve of the start-up pressure gradient and oil well production.

$0.025 \mathrm{MPa} / \mathrm{m} 、 0.03 \mathrm{MPa} / \mathrm{m}$ and $0.035 \mathrm{MPa} / \mathrm{m}$ separately. Get the production under the different start-up pressure gradient as shown in Fig. (6).

From the above curve we can see, the oil well production decreases with the increase of start-up pressure gradient in the case of other reservoir conditions unchanged and meet the linear relationship approximately. This is because the bigger the start-up pressure gradient is, the more resistance the fluid seepage needs to overcome. So in the case of other reservoir conditions unchanged, the oil well production decreases with the increase of start-up pressure gradient.

\subsection{Production Pressure Differential}

Design the different production pressure differential separately. Get the production under the different Production pressure differential as shown in Fig. (7).
From the curve above we can see, at the begining the oil well production increases with the increase of production pressure differential in the case of other reservoir conditions unchanged. When the production pressure difference reaches at a certain value, oil well production reaches the maximum and remains the same with the production pressure differential increase after.

\section{CONCLUSION}

(1) This paper has established the capacity model of the vertical fractured well production under the factors of Start-up pressure gradient, pressure sensitive effect and the artificial fracture length.

(2) The numerical calculation results show that: when the angle of artificial fracture and well array direction is $0^{\circ}$, the development effect is the best.

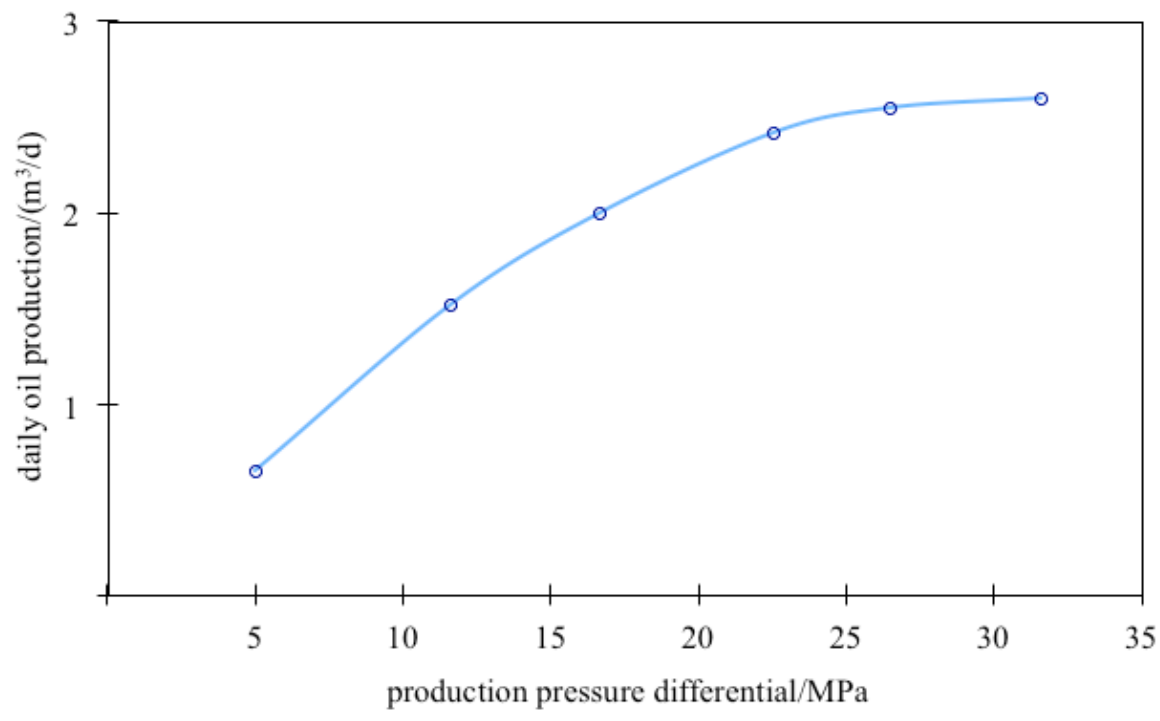

Fig. (7). Relationship curve of the production pressure differential and oil well production. 
(3) The oil well production decreases with the increase of start-up pressure gradient. With the increase of production time, increase the fracture length almost has no effect.

(4) The oil well production decreases with the increase of start-up pressure gradient in the case of other reservoir conditions unchanged and meet the linear relationship approximately. The oil well production increases with the increase of production pressure differential. When the production pressure difference reaches a certain value, oil well production reach the maximum and remains the same with the production pressure differential increase after.

\section{CONFLICT OF INTEREST}

The authors confirm that this article content has no conflict of interest.

\section{ACKNOWLEDGEMENTS}

This work was financially supported by the Natural Science Foundation of China under Grant No. 51474071.

\section{REFERENCES}

[1] J. Liu, Y. Su, A. Xueqing, Z. Zhao, and Z. Zhao, "Modeling of The Low Permeability Fracturing Gas Well Production Capacity," Energy Education Science and Technology Part A. Energy Science and Research, vol. 32, no.6, pp. 8367-8376, 2014.

[2] Y. Wang, X. Wu, F. Lai, R. Wang, M. Teng, Y. Wu, R. Liu, "Experimental Study on Factors Influencing Sweep Efficiency of Water Flooding Oil Reservoir," Energy Education Science and Technology Part A. Energy Science and Research, vol. 31, no.4, pp. 2363-2374, 2013.

[3] Y. Li, A. Chi, Y. Liu, and C. Gao, "The Breakdown Pressure Calculating Model for Open Hole Completion CBM Well Hydraulic Fracturing," The Open Fuels \& Energy Science Journal, vol. 7, pp. 12-19, 2014.

[4] W. Charles, "Review of Characteristics of Low Permeability," AAPJ, vol. 73, no.5, pp. 613-629, 1989.

[5] H. Zhang, S. He, G. Luan, C. Jiao, S. Mo, and H. Liu, "Quantifative Study of Stress Sensitivity in Ultralow Permeability Fracure Media Reservoir," Chinese Journal of Rock Mechanics and Engineering, pp. 3349-3354, 2014.

[6] E. Sun, X. Li, Weidong, and P. Wand, "Analysis of Water and Gas Two-phase Flow Well in Low Permeability Gas Reservoir," Lithologic Reservoirs, vol.06, pp.121-124, 2012.
[7] S. Zhang, H. Yin, H. Lv, and H. Zhou, "Production Analysis of Fracture Wells in the Low Permeability Naturally Fractured Gas Reservior," Science Technology and Engineering, vol. 08, pp.1848$1852,2010$.

[8] J. Liu, R. Liao, and Z. Yang, "Productivity Analysis of Hydraulically Fractured Gas Well in Low permeability-deformed media reservoirs," Fault-Block Oil \& Gas Field, vol. 03, pp.357359+372, 2011.

[9] Y. Li, and A. Chi, "The Calculation Model of Initiation Pressure During Hydraulic Fracturing Process of Perforated Coal Seams," The Open Fuels \& Energy Science Journal, vol. 6, pp. 30-35, 2013.

[10] G. Feng, Q. Liu, G. Shi, and Z. Lin, "An Unsteady Seepage Flow Model Consider Kickoff Pressure Gradient for Low Permeability Gas Reservoirs," Petroleum Exploration and Development, vol. 04, pp. 457-461, 2008.

[11] J. Guo, L. Zhang, and B. Liang, "Productivity Analysis of a Fracture Well in Low Permeability Gas Reservoirs Considering Threshold Pressure Gradient," Natural Gas Industry, vol. 07, pp. $45-47+131,2010$

[12] N. Zhang, X. Wang, F. Xu, S. Jia, and R. Yan, "Effects of Kickoff Pressure Gradient and Stress Sensitivity on the Productivity of Vertical Wells in Low Permeability Reservoirs," Special Oil \& Gas Reservoirs, vol. 01, pp. 74-77+139, 2012.

[13] H. Zhang, S. He, G. Luan, C. Jiao, S. Mo, and H. Liu, "Quantifative Study of Stress Sensitivity in Ultralow Permeability Fracture Media Reservior," Chinese Journal of Rock Mechanics and Engineering, pp. 3349-3354, 2014.

[14] F. Liu, Y. Wang, X. Chen, Y. Su, and Y. Wang, "Analysis on Oil Well Production of Low Permeability Reservoirs with Stresssensitivity being Taking into Consideration," Oil \& Gas Geology, vol. 01, pp.124-128, 2013.

[15] W.J. Lee, A. Texas, and S.A. Holditch, "Fracture Evaluation With Pressure Transient Testing in Low-Permeability Gas Reservoirs," SPE Journal of Petroleum Technology, vol. 33, no.9, pp. 1776$1792,1981$.

[16] D.N. Meehan, "Optimization of Fracture Length and Well Spacing in Heterogeneous Reservoirs," SPE Production \& Facilities, vol. 10, no.2, pp.82-88, 1995.

[17] Y. He, "Study on Well Pattern Arrangement of Low Permeability Reservoir by Reservoir Engineering Methods," Institute of porous flow and fluid mechanics, Chinese Academy of Science, 2009.

[18] X. Guo, and Y. Wu, "Influence of Start-up Pressure Gradient and Stress Sensitivity on Productivity of Low-permeability Gas Reservoir," Oil \& Gas Geology, vol. 04, pp.539-543, 2007.

[19] X. Wang, X. Song, B. Jiang, X. Cai, and G. Liu, "Numerical Simulation of Low-permeability Fractured Reservoirs on Imbibition," Science Technology and Engineering, vol. 07, pp.1952-1956, 2013.

[20] H. Cinco-Ley, "Transiet Pressure Analysis: Finite Conductivity Fracture Case Versus Damaged Frecture Case," SPE10179.

[21] M. Muskat, "The Flow of Homogeneous Fluids Through Porous Media," New York, Mc Graw-Hill, pp.25 35, 1937. 